Article

\title{
The Bioconcentration and Degradation of Nonylphenol and Nonylphenol Polyethoxylates by Chlorella vulgaris
}

\author{
Hong-Wen Sun *, Hong-Wei Hu, Lei Wang, Ying Yang ${ }^{\dagger}$ and Guo-Lan Huang
}

MOE Key Laboratory of Pollution Processes and Environmental Criteria,

College of Environmental Science and Engineering, Nankai University, Tianjin 300071, China;

E-Mails: hhw1070063@163.com (H.-W.H.); wang2007@nankai.edu.cn (L.W.); yangying@163.com (Y.Y.); yaotingyu@nankai.edu.cn (G.-L.H.)

$\dagger$ Present Address: Tianjin Dongjiang Entry-Exit Inspection and Quarantine Bureau of the People's Republic of China, Tianjin 300463, China; E-Mail: nmyangying@126.com.

* Author to whom correspondence should be addressed; E-Mail: sunhongwen@nankai.edu.cn; Tel./Fax: +86-22-350-9241.

Received: 12 December 2013; in revised form: 8 January 2014 / Accepted: 9 January 2014 / Published: 17 January 2014

\begin{abstract}
Nonylphenol polyethoxylates (NPnEOs), a major class of nonionic surfactants, can easily enter into aquatic environments through various pathways due to their wide applications, which leads to the extensive existence of their relative stable metabolites, namely nonylphenol (NP) and mono- to tri-ethoxylates. This study investigated the bioconcentration and degradation of NP and NPnEO oligomers $(n=1-12)$ by a green algae, Chlorella vulgaris. Experimental results showed that C. vulgaris can remove NP from water phase efficiently, and bioconcentration and degradation accounted for approximately half of its loss, respectively, with a $48 \mathrm{~h}$ BCF (bioconcentration factor) of $2.42 \times 10^{3}$. Moreover, C. vulgaris could concentrate and degrade NPnEOs, distribution profiles of the series homologues of the NPnEOs in algae and water phase were quite different from the initial homologue profile. The $48 \mathrm{~h} \mathrm{BCF}$ of the NPnEO homologues increased with the length of the EO chain. Degradation extent of total NPnEOs by C. vulgaris was $95.7 \%$, and only $1.1 \%$ remained in water phase, and the other $3.2 \%$ remained in the algal cells. The algae removed the NPnEOs mainly through degradation. Due to rapid degradation, concentrations of the long chain NPnEO homologous in both water $(n \geq 2)$ and the algal phase $(n \geq 5)$ was quite low at the end of a $48 \mathrm{~h}$ experiment.
\end{abstract}


Keywords: bioconcentration; degradation; nonylphenol; nonylphenol polyethoxylates; Chlorella vulgaris

\section{Introduction}

Nonylphenol polyethoxylates (NPnEOs) are one class of most widely used non-ionic surfactants. Internationally, NPnEOs have been used in many different industrial processes, such as laundering, textile processing (wetting and scouring), pulp and paper processing, paint and resin formulation, oil and gas recovery, steel manufacturing, pest control and power generation for over 50 years [1-3]. The wide use of products containing NPnEOs made these compounds frequently detected in the environment. The environmental fate of NPnEOs has been well documented [4-6], and about $60 \%$ of the surfactant production enters into the aquatic environment via various pathways such as municipal and industrial wastewater discharges and sewage treatment plant effluents [7]. NPnEOs are partially converted to more persistent and toxic metabolites such as nonylphenol (NP), short chain mono- to triexthoxylates (i.e., NP1EO, NP2EO, NP3EO) [4,8-12], and hence, these compounds frequently coexist in surface waters as the result of discharges from waste water treatment plants that are inefficient at removing nonylphenolic compounds.

Some of the degradation products, especially NP, are more lipophilic and consequently much more toxic than their parent compounds [6,13-16]. Moreover, it has been confirmed that NP and their polyethoxylates have antiandrogenic activity, for instance, disturbing the proper functioning of androgens that are essential for the normal development of males and their reproductive systems for both marine and fresh water species [17,18]. Other adverse effects were also reported. For examples, they have a significant toxic effect on hepatocytes in vivo [19], and on splenocytes and sertoli cells in vitro $[14,20]$. Hence, the widespread use of NPnEOs, coupled with the frequent detection of their relatively stable toxic metabolites, has led to restrictions in their production and application. The European Directive No. 2003/53/EC [21] prohibited the use of NP and its ethoxylates in the European Union. The U.S. Environmental Protection Agency (U.S. EPA) has issued a specific action plan [22] to support and encourage the ongoing voluntary phase-out of NPnEOs in industrial laundry detergents in order to manage potential risks from NPnEOs. However, the application is not prohibited globally, and relatively high concentrations of NPnEOs and NP were still found in rivers and lakes in China, Japan, USA and other countries, with concentrations varying widely from tens of nanograms per liter to more than one hundred micrograms per liter [23-30], particularly in areas affected by wastewater effluents [31-35].

The occurrence of NP and other NPnOEs biodegradation metabolites in surface waters has been studied extensively and a substantial body of research has been developed about the toxicity and bioconcentration of these compounds [36-41]. Degradation of NP, NP1EO has been studied with aerobic microorganisms and anaerobic microorganisms, respectively. Under aerobic conditions, Yuan et al. [42] found that Pseudomonas sp. expressed the best biodegrading ability among several microorganism species tested. Chang et al. [43] observed degradation of NP and NP1EO under different anaerobic conditions and the results showed that the degradation rates follow an order of 
sulfate-reducing condition $>$ methanogenic conditions $>$ nitrate-reducing conditions. Though with relatively high water solubility, the NPnEOs, and especially their small metabolites that have relatively greater lipophilicity, show substantial bioaccumulation factors. The estimated bioconcentration factors in fish tissues range from 13-410 for NP, 3-300 for NP1EO and 3-330 for NP2EO [44].

Although the toxic or inhibitory levels of NP and NPnEOs on algae were successfully identified in previous studies [1,13,36,45-48], little is known about the bioconcentration and biodegradation of NP and NPnEOs by microalgae. Among aquatic organisms, microalgae play an important role in the monitoring of aquatic pollution because they are at the bottom of the aquatic food chain, and the concentration of pollutants in algae may be transferred to organisms at higher trophic levels through the food chain. Moreover, algae have been shown to be capable of degrading organic pollutants including aromatic compounds, azo dyes, phthalates and tributyltin [49-51]. Thus, proliferation of an algal component may enhance the degradation process of a chemical in an aquatic environment. Only a few studies have reported the bioconcentration of NP and NPnEO in algae. Ahel et al. [44] reported that rather high concentrations of NP, NP1EO, and NP2EO occur in macrophytic algae, particularly in Cladophora glomerata, with bioconcentration factors of NP of up to 10,000. Correa-Reyes et al. [15] studied NP algal bioconcentration using microalgae Isochrysis galbana, and found that the algae was able to bioconcentrate NP by 6940 times. However, the biodegradation of NPnEO and NP by microalgae has never been studied. Therefore, the present work undertakes an investigation on the concentration and degradation of NP and NPnEOs $(n=1-12)$ by a green algae, Chlorella vulgaris. The bioconcentration tendency of NPnEO homologues with different chain lengths was discussed. Moreover, the contributions of bioconcentration and biodegradation to the dissipation of NPnEO in an aquatic environment were analyzed.

\section{Results and Discussion}

\subsection{Bioconcentration and Biodegradation of NP by $\mathrm{C}$. vulgaris}

Considerable NP was concentrated in the algal cells (Figure 1), which increased quickly with time first and stabilized or even diminished a little after a maximum was arrived. The concentrations of NP in the algae were $98.3 \mu \mathrm{g} / \mathrm{g}$ at $24 \mathrm{~h}$ (peak) and $86.9 \mu \mathrm{g} / \mathrm{g}$ at $48 \mathrm{~h}$, respectively. Accordingly, the concentration of NP in water declined rapidly in the first $2 \mathrm{~h}$ to $53.7 \%$ of the initial concentration of $200 \mu \mathrm{g} / \mathrm{L}$, after that, the changes of concentration of NP was not so dramatic, and NP decreased to $74.7 \%$ at $14 \mathrm{~h}$ and $82.1 \%$ at $48 \mathrm{~h}$, respectively. Correa-Reyes et al. [15] also found that bioconcentration of NP in algae is a rapid process, and after I. galbana was incubated with $100 \mu \mathrm{g} / \mathrm{L} \mathrm{NP}$ for only $1 \mathrm{~h}$, most of the NP was accumulated in the algal cells and almost no free NP remained in the medium.

Bioconcentration factor (BCF) was calculated by the ratio of the concentrations in the algae and in the aqueous phase (Figure 1) [52]. BCF was 2422 at $48 \mathrm{~h}$, and 2001 at $24 \mathrm{~h}$. A little bigger BCF was achieved at $48 \mathrm{~h}$ due to the fact that both the concentrations in the algae and water phase had decreased since those at $24 \mathrm{~h}$. This indicated that NP was degraded in the algae culture. Besides, the algal density increased a little during the experiment, which may also lead to the reduction of NP concentration in the algae due to the growth dilution effect. 
Figure 1. Nonylphenol (NP) concentrations in algal cells and water phase, and bioconcentration factors (BCFs) of NP in algal cells with time during incubating C. vulgaris in $200 \mu \mathrm{g} / \mathrm{L}$ NP solution.

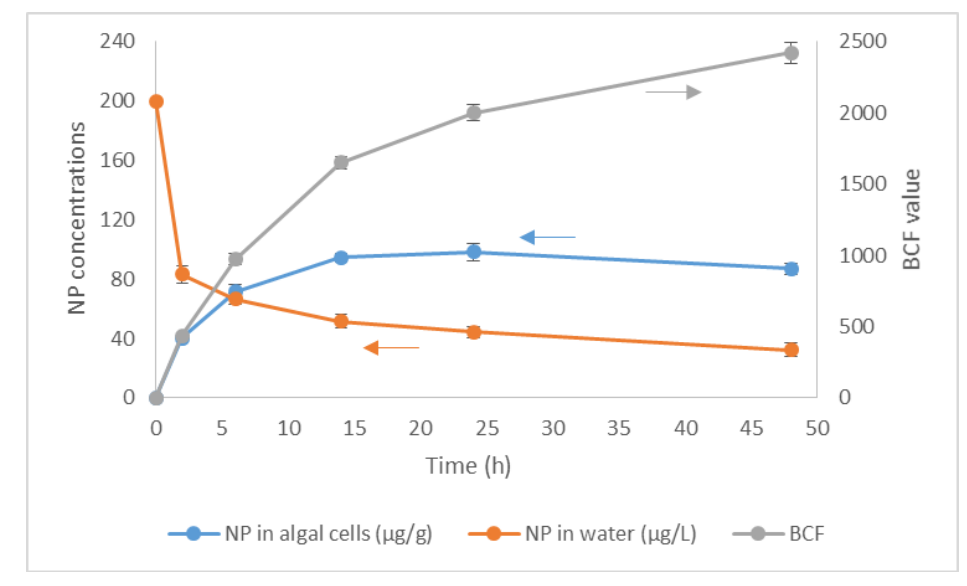

To confirm the degradation of NP in the algal culture, the total NP mass in the culture was calculated (Figure 2). It can be seen that based on the total mass of NP in algal cells and water phase, NP degradation was rapid during the initial period. The degradation ratio was $48.0 \%$ at $2 \mathrm{~h}$, and then the degradation slowed down, with degradation efficiencies of $52.6 \%$ at $6 \mathrm{~h}$ and $56.7 \%$ at $24 \mathrm{~h}$, respectively. It should also be noted here that an unknown peak appeared on the chromatogram after NP, which could not be identified as the breakdown product of NP, and it should be an oxidative conjugate NP [53] and need further study.

Figure 2. Time dependent NP biodegradation efficiency by C. vulgaris based on the total NP mass lost in algae and water phase.

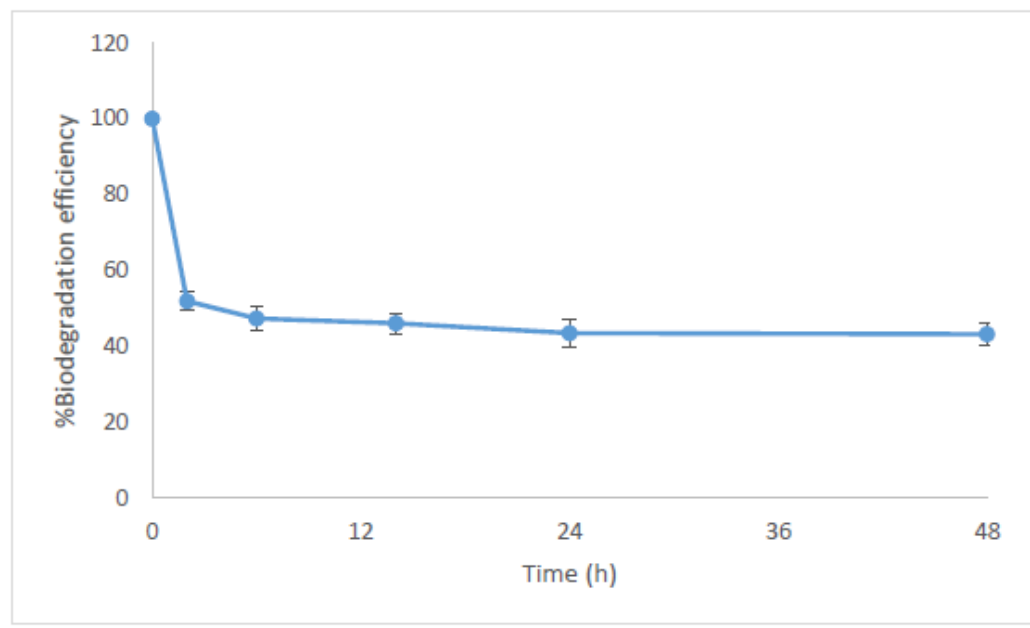

The bioaccumulation of NP in aquatic organisms at different trophic levels was widely studied [36]. The freshwater algae, fish and invertebrates have been tested in the laboratory [5]. Snyder et al. [54] reported BCFs of 245-380 in fathead minnow. As for saltwater species, Ekelund et al. [55] reported a BCF of 12,500 in stickleback (Gasterosteus aculeatus). Correa-Reyes et al. [15] reported microalgae I. galbana was able to bioconcentrate NP by 6940 times, where $77 \%$ of the initial NP is accumulated intracellularly after $1 \mathrm{~h}$ of incubation, suggesting that the bioconcentration of NP in freshwater algae is 
considerable. Apart from the studies of bioaccumulation of NP, the degradation of NP by microorganisms has also accumulated a lot of data. Chang et al. [42,56,57] conducted tests on the anaerobic degradation of NP by microorganisms in sludge, river sediment and mangrove sediment. They isolated pure microbial strains from sludge samples and eight bacterial strains were capable of degrading NP anaerobically, using it as a carbon source. Gabriel et al. [58] described the bacterial metabolism of several NP isomers and found that the initial reaction of NP degradation was anipso-hydroxylation producing 4-alkyl-4-hydroxy-cyclohexadienones. Microorganisms and rat liver microsomes use the same type of mechanism to detach different substituents in ortho- and para-substituted phenols. In this experiment, the degradation of NP by microalgae was for the first time reported and it is obvious that $C$. vulgaris can degrade NP effectively.

\subsection{Bioconcentration and Biodegradation of NPnEOs $(\mathrm{n}=1-12)$ by $\mathrm{C}$. vulgaris}

Figure 3 illustrates the initial concentration distribution profiles of all homologues of the tested NPnEOs $(n=1-12)$ in water, which is showing a Poisson distribution. The maximum concentration appears at NP9EO and NP10EO, the concentration of bilateral homologues shows a declining trend, and NP1EO was almost undetected.

Figure 3. Initial concentration distribution profiles of the nonylphenol polyethoxylates (NPnEO) homologues $(n=1-12)$.

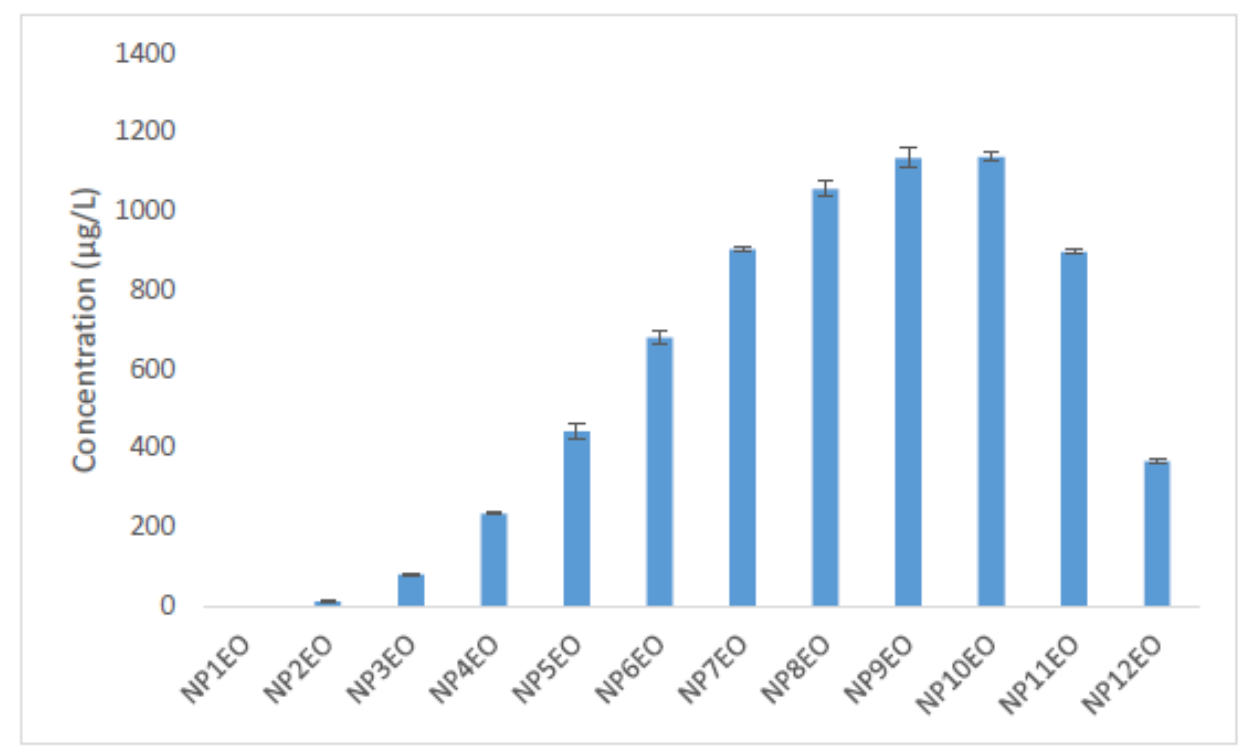

Figure 4 shows the concentration of all NPnEO homologues $(n=1-12)$ in the algal cells of C. vulgaris. NP1EO had the highest concentration in algal cells, and the enrichment reduced gradually with the increasing number of EO groups. Comparatively speaking, the enrichment of short chain NPnEOs $(n<5)$ was bigger than the longer homologues $(n \geq 5)$. The two homologues with the longest EO chain, NP11EO and NP12EO, could not be detected in the algae though their concentrations in water were substantially high (Figure 3). This is mainly due to the different lipophilicity of the different homologues. As the number of EO groups increases, the lipophilicity of the homologues decreases [59-61]. Besides, when a chemical molecule is too large, it becomes difficult for the 
chemical to penetrate the biomembrane. In addition, the homologues with long EO chains can be degraded more quickly than those with short chain homologues [62].

Figure 4. Time-dependent bioconcentration of the homologues of NPnEOs $(n=1-12)$ in C. vulgaris.

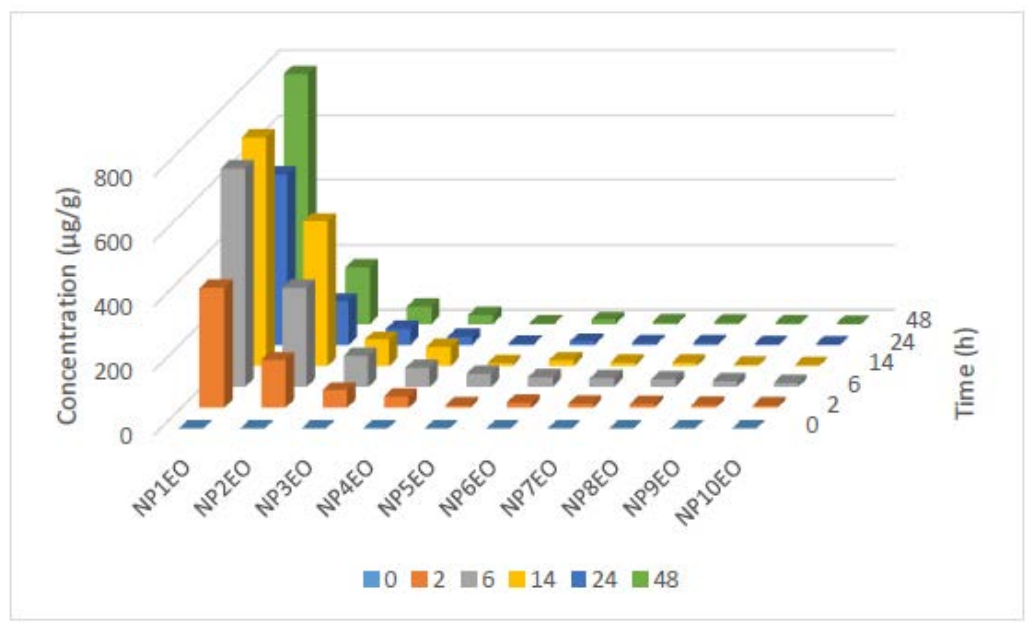

The bioconcentration kinetics of the different NPnEO homologues by C. vulgaris varied a lot (Figure 4). The concentration of NP1EO in C. vulgaris reached $372.4 \mu \mathrm{g} / \mathrm{g}$ at $2 \mathrm{~h}$; increased gradually to $706.3 \mu \mathrm{g} / \mathrm{g}$ at $14 \mathrm{~h}$; and at the end of $48 \mathrm{~h}$ experiment, reached the maximum value of $772.3 \mu \mathrm{g} / \mathrm{g}$. Compared with the other long chain homologues, it is evident that NP1EO showed the greatest accumulation. Different from NP1EO that the concentration showed an increasing trend along the whole experiment course, other homologues all showed a peak value. The peak is due to the simultaneous absorbance and degradation in algal cells. NP2EO also showed a substantial concentration, with the maximum concentration of $447.4 \mu \mathrm{g} / \mathrm{g}$ at $14 \mathrm{~h}$. The concentrations of NP3-4EO were relatively lower as compared to NP1-2EO, reaching peak values of 96.1 and $59.2 \mu \mathrm{g} / \mathrm{g}$, respectively. The concentrations of longer chain homologues were further lower, and at $6 \mathrm{~h}$, the concentrations reached the maximum values of $41.2 \mu \mathrm{g} / \mathrm{g}$ for NP5EO, $29.7 \mu \mathrm{g} / \mathrm{g}$ for NP6EO, $26.4 \mu \mathrm{g} / \mathrm{g}$ for NP7EO, $23.3 \mu \mathrm{g} / \mathrm{g}$ for NP8EO, $18.9 \mu \mathrm{g} / \mathrm{g}$ for NP9EO and $12.9 \mu \mathrm{g} / \mathrm{g}$ for NP10EO, respectively.

Figure 5. Variation of concentration of the $\operatorname{NPnEO}(n=1-12)$ homologues in water phase.

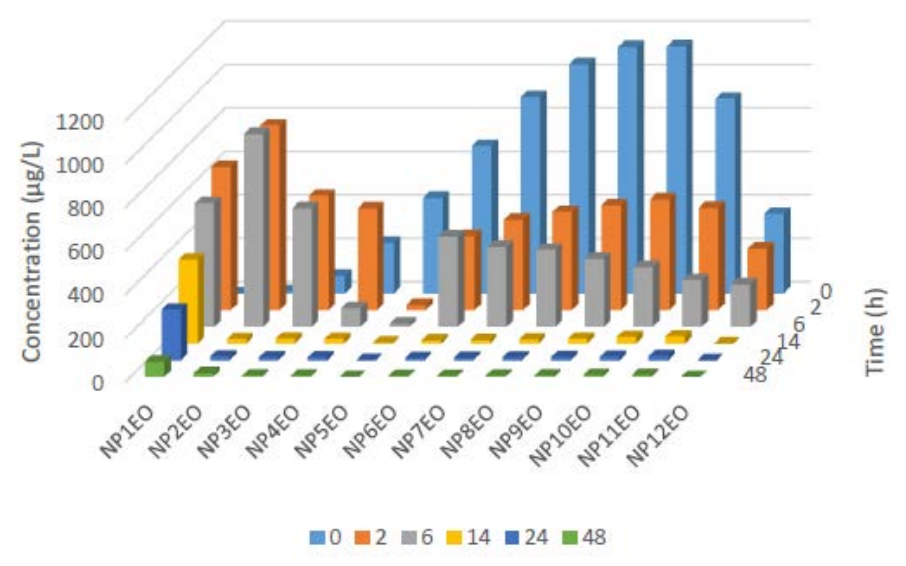


The water phase concentration of the NPnEO homologues also followed different changing trends. The concentrations of short chain NPnEOs $(n<5)$ in water appeared an increasing trend in the initial period (2-6 h), and then decreased (Figure 5). Oppositely, the concentration of long chain NPnEOs $(n \geq 5)$ decreased constantly in the course of experiment, except that NP6EO showed a slight increase during 2-6 h. The dramatic reduction of the long chain NPnEOs could not be explained solely by the uptake by the algae, for NP11EO and NP12EO, was not detected in the algal cells. Degradation is the main reason for the reduction of long chain NPnEOs. This could be confirmed by the increase in water concentration of short chain NPnEO. The accumulation of short chain NPnEOs both in water phase and algal cells during the initial period of the experiment is due to the fact that long chain NPnEOs have greater degradation rates than the short ones. It has been recognized that NPnEOs initially break down into a series of biodegradation intermediates, including low-mole ethoxylates (retaining mainly one- and two-mole ethoxylate units), ether carboxylates (carboxylation of the ethoxylate group) [11,63]. At the end of the $48 \mathrm{~h}$ experiment, the concentration of all NPnEO homologues $(n=1-12)$ in water is very low, except for NP1EO and NP2EO, which demonstrates that $C$. vulgaris can remove NPnEOs $(n=1-12)$ effectively in water.

Table 1. BCFs of NPnEO homologues $(n=1-10)$ by $C$. vulgaris at different times.

\begin{tabular}{cccccc}
\hline \multirow{2}{*}{ Homologue } & \multicolumn{5}{c}{ BCF at different time (h) } \\
\cline { 2 - 6 } & 2 & 6 & 14 & 24 & 48 \\
\hline NP1EO & 564 & 1186 & 1857 & 2271 & 11,028 \\
NP2EO & 174 & 345 & 22,350 & 7500 & 10,294 \\
NP3EO & 103 & 176 & 3727 & 3571 & 6750 \\
NP4EO & 75 & 682 & 2950 & 1821 & 4000 \\
NP5EO & 343 & 2783 & 2204 & 3357 & 7065 \\
NP6EO & 49 & 72 & 1200 & 1100 & 2416 \\
NP7EO & 32 & 71 & 725 & 585 & 1270 \\
NP8EO & 27 & 65 & 579 & 485 & 874 \\
NP9EO & 19 & 61 & 204 & 232 & 459 \\
NP10EO & 15 & 48 & 86 & 136 & 171 \\
Total NPnEOs & 155 & 448 & 6563 & 5406 & 13,831 \\
\hline
\end{tabular}

BCF values of all the NPnEO homologues in C. vulgaris were calculated for all the sampling times (Table 1). The time dependent trend of BCF was not the same with those of algal concentrations. This is because both algal phase concentration and water phase concentration varied intricately due to the simultaneous biodegradation and uptake of NPnEO by the algae. Generally, BCF reached a peak value at the end of experiment due to the low water phase concentration. The maximum BCF of single NPnEO homologue occurred at $14 \mathrm{~h}$ for NP2EO, indicating the successive degradation from long chain homologues to short chain ones inside the algal cells. The $48 \mathrm{~h}$ BCFs of NPnEO homologues in C. vulgaris ranged from 171-11,028, declining with increasing EO chain, with an exception of NP4EO. This demonstrates the remarkable discrepancy in eco-risk of different NPnEO homologues. The exception of NP4EO could be explained by the relative biodegradation rates and relative bioconcentration tendencies of different NPnEO homologues. 
To clarify the dissipation pathways of NPnEOs, the loss due to degradation were calculated based on mass balance (Figure 6). It can be found that the removal rate of NPnEOs $(n=1-12)$ in water was very fast in the first $2 \mathrm{~h}$, which became relatively slower after $2 \mathrm{~h}$. The concentration of the total NPnEOs $(n=1-12)$ reduced to $0.21 \mu \mathrm{g} / \mathrm{L}$ at $14 \mathrm{~h}$, which is $3.01 \%$ of the initial concentration, which means $97.0 \%$ of the initial $16.94 \mathrm{mg} / \mathrm{L} \mathrm{NPnEO}$ was removed from water. After $14 \mathrm{~h}$, the concentration of NPnEOs $(n=1-12)$ remained relatively constant, and the removal ratio reached $98.9 \%$ at the end of the experiment.

Figure 6. Dissipation of the total NPnEOs $(n=12)$ in the algal $(C$. vulgaris $)$ culture water.

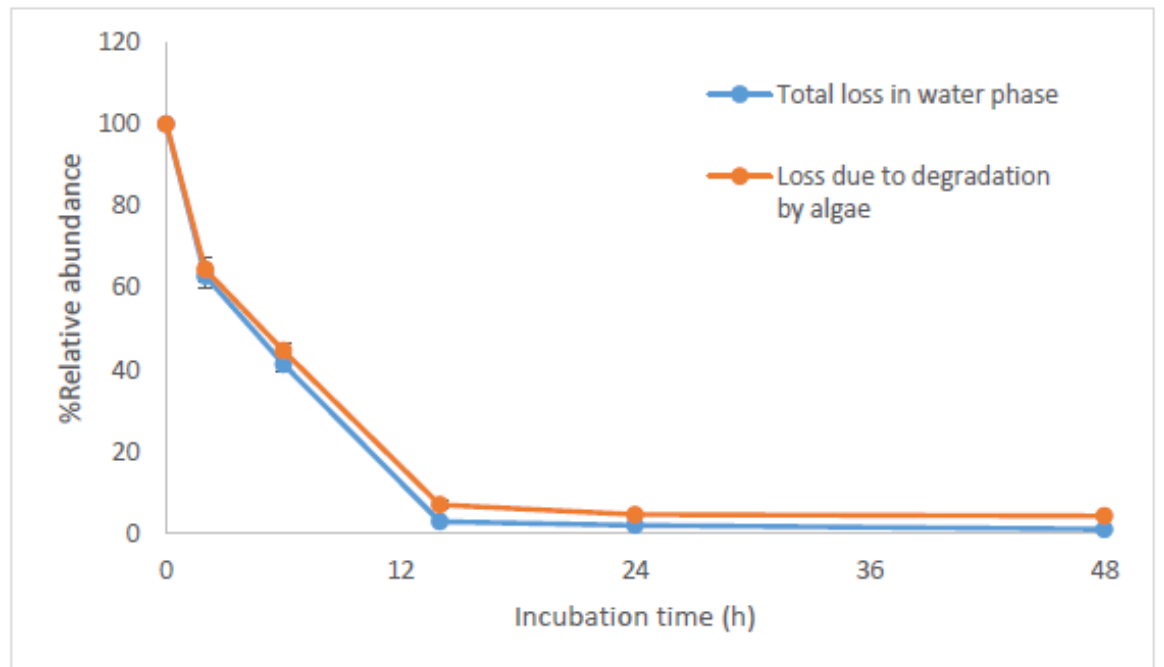

Degradation followed similar kinetic trend with the total dissipation. The degradation rate of NPnEOs $(n=1-12)$ by $C$. vulgaris was fast in the first $14 \mathrm{~h}$, reaching a maximum rate of $3.84 \mathrm{mg} / \mathrm{h}$ at $2 \mathrm{~h}$ and falling to $1.04 \mathrm{mg} / \mathrm{h}$ in the period of $2-14 \mathrm{~h}$ (Figure 6). The degradation efficiency was $92.9 \%$ at $14 \mathrm{~h}$, and the concentration of NPnEOs $(n=1-12)$ in water reduced to $0.49 \mathrm{mg} / \mathrm{L}$ from the initial concentration $(16.94 \mathrm{mg} / \mathrm{L})$. The degradation continued after $14 \mathrm{~h}$, but the degradation rate was so slow that the degradation efficiency just increased $2.8 \%-95.7 \%$. It is evident that NPnEOs ( $n=1-12$ ) degradation is rapid and almost complete within the first $14 \mathrm{~h}$, which has a similar tendency with NPnEOs $(n=1-12)$ degradation using acclimated sludge [64]. The removal rates of all NPnEO homologues $(n=1-12)$ by $C$. vulgaris are listed in Table 2 . Apart from NP1EO and NP2EO, the other homologues were degraded by $C$. vulgaris almost by $100 \%$ after $48 \mathrm{~h}$ experiment. Jonkers et al. [62] investigated the kinetics of aerobic biodegradation of NPnEOs $(n=4-15)$ in a laboratory scale bioreactor filled with river water, the concentration of NPnEOs $(n=4-15)$ reduced to $50 \%$ after $10 \mathrm{~h}$ and over $99 \%$ of the initial NPnEOs was degraded after 4 days. The long chain NPnEOs degraded to short chain NPnEOs in aerobic conditions with a relative fast rate in both studies. In this study, NP1EO and NP2EO were accumulated in water phase due to their slow degradation rates (Table 2).

In the experiment, NP was detected as one of the metabolites both in water and algal cells. As shown in Figure 7, the concentration of NP in water and algal cells reached the maximum at $6 \mathrm{~h}$, and then declined to a minimum at $14 \mathrm{~h}$ in water and $24 \mathrm{~h}$ in the algal cells, followed by a slight elevation. During the first $6 \mathrm{~h}$, the increasing concentration of NP could be due to the degradation of NPnEOs. It has been reported that besides to the consecutive shortening of EO chain (Figure 8), short 
chain NPnEOs can be oxidized to the corresponding nonylphenoxyethoxy acetic acids (NPnEC) [62], then breakdown to NP. We did detect NPnEC (not quantified) in the experimental system, both breakdown pathways might have been involved in the degradation of NPnEOs. It is the involvement of NPnEC that leads to the similar complicated change tendency of NP, NP1EO and NP2EO, especially in algae cells, which first increased and then decreased and increased again. The second elevation is thought to be the result of degradation of NPnEC.

Table 2. Removal rates of all NPnEO homologues $(n=1-12)$ by C. vulgaris in $48 \mathrm{~h}$.

\begin{tabular}{ccc}
\hline Homologue & $\begin{array}{c}\text { Removal rate of NPnEO } \\
\text { homologue in water phase (\%) }\end{array}$ & $\begin{array}{c}\text { Degradation rate of NPnEO } \\
\text { homologue in algal culture (\%) }\end{array}$ \\
\hline NP1EO & $-1356^{*}$ & - \\
NP2EO & $-1.59^{*}$ & - \\
NP3EO & 89.6 & 88.0 \\
NP4EO & 96.9 & 97.7 \\
NP5EO & 99.9 & 88.7 \\
NP6EO & 99.1 & 98.6 \\
NP7EO & 99.4 & 99.0 \\
NP8EO & 99.3 & 98.8 \\
NP9EO & 99.3 & 98.8 \\
NP10EO & 99.1 & 98.6 \\
NP11EO & 98.8 & 98.7 \\
NP12EO & 100 & 100 \\
\hline
\end{tabular}

* The negative sign means increase in mass.

Figure 7. Concentration variation of NP in water and algal cells during the bioconcentration and biodegradation of $16.94 \mathrm{mg} / \mathrm{L} \mathrm{NPnEO}(n=1-12)$ by $C$. vulgaris.

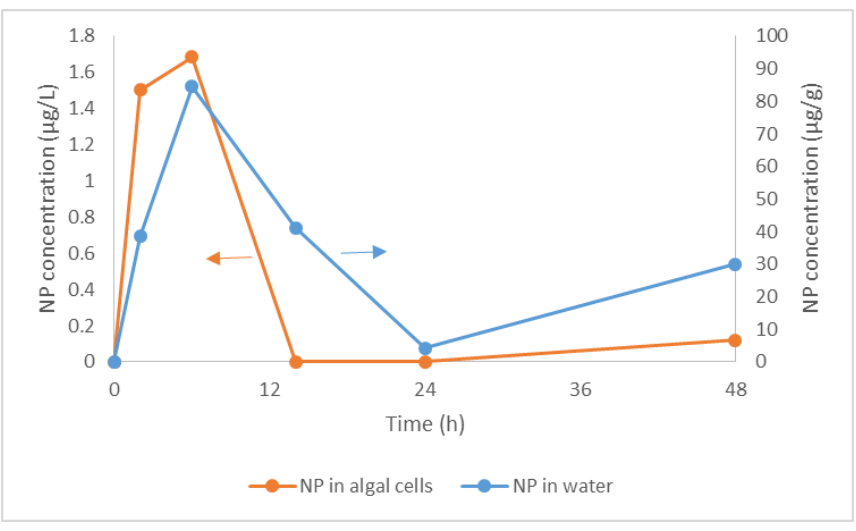

Figure 8. Aerobic biodegradation pathway of NPnEOs [62].

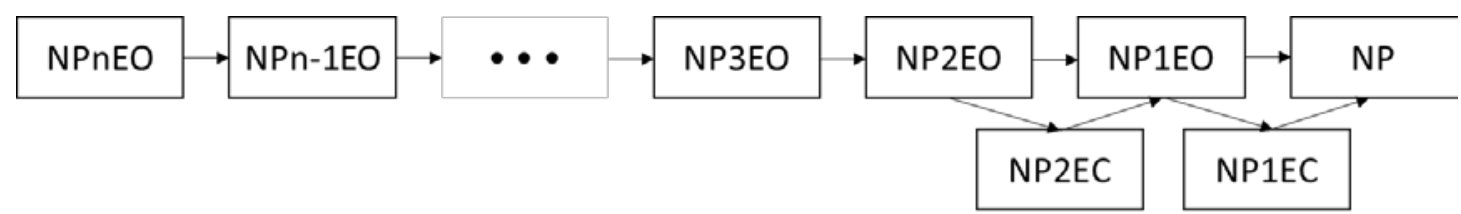

BCF of NP was about 50,000 at $6 \mathrm{~h}$ and 252,000 at $48 \mathrm{~h}$. These values are much higher than the data above when NP was spiked alone and in the literature, which suggests that degradation of 
NPnEOs occurred inside the algal cells. Hence, as a metabolite of degradation, NP accumulated in the algae, and steady state of bioconcentration between the algae and water had not been achieved.

\section{Experimental Section}

\subsection{Chemicals and Algae}

The standard of NP and NPnEOs $(n=1-15)$ were purchased from Tokyo Chemical Industry (Tokyo, Japan) and Hayashi Pure Chemical (Osaka, Japan), respectively, with the purity of 99.9\%. An industrial product was purified by collecting HPLC elute of NPnEOs $(n=1-12)$ and used in bioconcentration and degradation test, and its concentration and homologue distribution was determined. The freshwater green algae, Chlorella vulgaris, were bought from the Institute of Hydrobiology, Chinese Academy of Science, Wuhan, China. They were cultured sterilely in Bold Basal medium at $25 \pm 1{ }^{\circ} \mathrm{C}$ [65]. The light intensity was $50 \mathrm{mmol}$ photons $/ \mathrm{m}^{2} / \mathrm{s}$ with a 12:12 light-dark cycle.

\subsection{Bioaccumulation and Biodegradation of NP and NPnEOs by $\mathrm{C}$. vulgaris}

The tests were carried out in 3-L Erlenmeyer flasks with concentration fixed at $200 \mu \mathrm{g} / \mathrm{L}$ for NP and $16.94 \mathrm{mg} / \mathrm{L}$ for NPnEOs $(n=1-12)$, respectively. The Bold Basal medium was the base solution when the tests were conducted and the algal cells were acclimated in the medium under the same conditions as mentioned above. After arriving at the middle exponential growth phase, the cells were collected, rinsed with the fresh medium and then resuspended into the different test media under sterilization condition, the initial cell density was in the range of $1-2 \times 10^{5}$ cells $/ \mathrm{mL}$. The algal culture was shaken every three hours to ensure the exchange of gases. A $500 \mathrm{~mL}$ aliquot was taken out at 2, 6, 14, 24 and $48 \mathrm{~h}$, respectively, and divided into two samples for duplicate analysis. After separating algal cells from water by filtration using the $0.45 \mu \mathrm{m}$ fiber filter, the concentrations of NP and NPnEOs were determined both in algal cells and in culture solution. Control was conducted as the same condition without the introduction of algae.

\subsection{Sample Pre-Treatment}

Water samples were subjected to a concentration and clean-up step by solid-phase extraction (SPE) using Waters Oasis TM HLB cartridges (Milford, MA, USA) [66]. The SPE cartridges were preconditioned with $2.0 \mathrm{~mL}$ of DCM/methanol $(50 / 50, v / v)$, followed by $1.0 \mathrm{~mL}$ of methanol, and then equilibrated with $1.0 \mathrm{~mL}$ of super-pure water. The samples were passed through the cartridge at a flow rate of $1 \mathrm{~mL} / \mathrm{min}$, and the cartridge was cleaned with $1.0 \mathrm{~mL}$ of methanol/water $(95 / 5, v / v)$ and eluted with $2.0 \mathrm{~mL}$ of $\mathrm{DCM} /$ methanol $(50 / 50, v / v)$. The eluent was evaporated to almost dryness at $0.008 \mathrm{MPa}, 50-52{ }^{\circ} \mathrm{C}$ in a water bath, and $1.0 \mathrm{~mL}$ of $n$-hexane was then added to redissolve the residue before HPLC analysis.

Liquid-liquid extraction was used to extract the NP and NPnEOs $(n=1-12)$ in algal cells. The algal cells were suspended in $8 \mathrm{~mL}$ of water, and crushed by ultrasonic cell-crushed-apparatus for $2 \mathrm{~min}$ after being freezed-thawed for 4 cycles in the darkness. The crushed algal cells were extracted twice using 4-mL dichloromethane, and the organic phase was combined and evaporated to almost dryness 
by rotary evaporation. The residue was redissolved in $1.0 \mathrm{~mL}$ of $n$-hexane, and the solution was filtrated using $0.45 \mu \mathrm{m}$ organic film prior to HPLC (High Performance Liquid Chromatography) analysis.

\subsection{HPLC Analysis}

The HPLC analysis was performed using a Waters 1552 high performance liquid chromatograph equipped with a fluorescence detector and a Millennium software package [66]. A $\mu$ Bondapak Amino

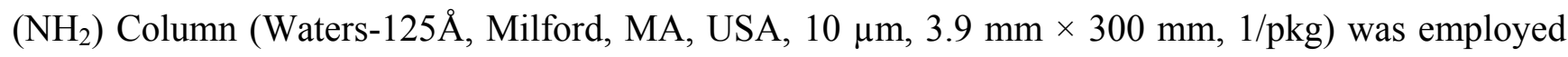
under ambient temperature. Mobile phase flew at a flow rate of $1.0 \mathrm{~mL} / \mathrm{min}$ and the injection volume was $20 \mu \mathrm{L}$. Separation was performed with a linear gradient elution of solvent A ( $n$-hexane/isopropanol $(98 / 2, v / v))$ and solvent B (isopropanol/water, $(98 / 2, v / v)$ ) (Table 3). The fluorescence detection was achieved at an excitation wavelength of $233 \mathrm{~nm}$ and an emission wavelength of $302 \mathrm{~nm}$. The analytical method can simultaneously quantify NPnEOs $(n=1-12)$ and their small inter-metabolites in samples. The detection limits of the method are $0.01 \mu \mathrm{g} / \mathrm{L}$ for NP and NP1EO, $0.02 \mu \mathrm{g} / \mathrm{L}$ for NP2EO and NP3EO, $0.05 \mu \mathrm{g} / \mathrm{L}$ for NP4EO and the following long chain homologues, respectively. Recoveries for different NPnEOs and NP were larger than $90 \%$ in water phase and $88 \%$ in algae.

Table 3. The linear elution gradient for HPLC analysis of NPnEOs and their small metabolites.

\begin{tabular}{|c|c|c|}
\hline Time (min) & $n$-hexane/isopropanol $(98 / 2, v / v)$ & isopropanol/water $(98 / 2, v / v)$ \\
\hline 0 & 5 & 95 \\
\hline 30 & 50 & 50 \\
\hline 35 & 70 & 30 \\
\hline 40 & 65 & 35 \\
\hline 45 & 50 & 50 \\
\hline 55 & 5 & 95 \\
\hline
\end{tabular}

\section{Conclusions}

Bioconcentration and degradation of NP and NPnEOs $(n=1-12)$ by a pure culture of $C$. vulgaris were studied for the first time. NP and NPnEOs $(n=1-12)$ can be concentrated by $C$. vulgaris, and the $48 \mathrm{~h} \mathrm{BCFs}$ were 2422 and 13,831, respectively. BCF increased as the EO chain became shorter. Biodegradation of both NP and NPnEOs did occur, which accounted for 56.7\% of NP loss and 98.7\% of NPnEOs loss in water, respectively. The high BCF value of NPnEOs compared to NP is thought to be due to the biodegradation, which is thought to occur in algal cells and generate NP and short chain NPnEOs, such as NP1EO and NP2EO. The degradation products of NPnEOs were mainly NP, NP1EO and NP2EO, and the content of NP1EO was the largest at the end of the $48 \mathrm{~h}$ experiment. Though not quantified, NPnEC was detected, and the degradation pathway through NPnEC is thought to account for the complicate change in concentration of NP1EO, NP2EO and NP, especially in algal cells.

As primary producers of aquatic ecosystem, microalgae can concentrate a mass of NP and NPnEOs $(n=1-12)$ which can be transferred to organisms at higher trophic levels through the food chain, such as invertebrate Daphnia magna. In addition, the degradation products - for instance, short chain NPnEO homologues and NP-exhibit greater toxicity than the parent compounds. Thus, this work 
shows that the environmental fate of NP and NPnEOs concentrated by microalgae should be considered as a risk for the organisms living in the same ecosystem.

\section{Acknowledgments}

This study was supported by Ministry of Science and Technology of China (2012BAC07B02); Natural Science Foundation of China (41073087); and Ocean Promotion Plan of Tianjin Ocean Bureau (KJXH2012-22).

\section{Conflicts of Interest}

The authors declare no conflict of interest.

\section{References}

1. Staples, C.A.; Weeks, J.; Hall, J.F.; Naylor, C.G. Evaluation of aquatic toxicity and bioaccumulation of C8- and C9- alkylphenol ethoxylates. Environ. Toxicol. Chem. 1998, 17, 2470-2480.

2. Bettinetti, R.; Cuccato, D.; Galassi, S.; Provini, A. Toxicity of 4-nonylphenol in spiked sediment to three populations of Chironomus riparius. Chemosphere 2002, 46, 201-207.

3. Kannan, K.; Keith, T.L.; Naylor, C.G.; Staples, C.A.; Snyder, S.A.; Giesy, J.P. Nonylphenol and nonylphenol ethoxylates in fish, sediment, and water from the Kalamazoo River, Michigan. Arch. Environ. Con. Tox. 2003, 44, 77-82.

4. Ying, G.-G.; Williams, B.; Kookana, R. Environmental fate of alkylphenols and alkylphenol ethoxylates-A review. Environ. Int. 2002, 28, 215-226.

5. Vazquez-Duhalt, R.; Marquez-Rocha, F.; Ponce, E.; Licea, A.F.; Viana, M.T. Nonylphenol, an integrated vision of a pollutant. Appl. Ecol. Env. Res. 2005, 4, 1-25.

6. Soares, A.; Guieysse, B.; Jefferson, B.; Cartmell, E.; Lester, J. Nonylphenol in the environment: A critical review on occurrence, fate, toxicity and treatment in wastewaters. Environ. Int. 2008, 34, 1033.

7. Fytianos, K.; Pegiadou, S.; Raikos, N.; Eleftheriadis, I.; Tsoukali, H. Determination of non-ionic surfactants (polyethoxylated-nonylphenols) by HPLC in waste waters. Chemosphere 1997, 35, $1423-1429$.

8. Ahel, M.; Schaffner, C.; Giger, W. Behaviour of alkylphenol polyethoxylate surfactants in the aquatic environment-III. Occurrence and elimination of their persistent metabolites during infiltration of river water to groundwater. Water Res. 1996, 30, 37-46.

9. Staples, C.A.; Naylor, C.G.; Williams, J.B.; Gledhill, W.E. Ultimate biodegradation of alkylphenol ethoxylate surfactants and their biodegradation intermediates. Environ. Toxicol. Chem. 2001, 20, 2450-2455.

10. Venkatesan, A.K.; Halden, R.U. National inventory of alkylphenol ethoxylate compounds in US sewage sludges and chemical fate in outdoor soil mesocosms. Environ. Pollut. 2013, 174, 189-193.

11. Field, J.A.; Reed, R.L. Nonylphenol polyethoxy carboxylate metabolites of nonionic surfactants in US paper mill effluents, municipal sewage treatment plant effluents, and river waters. Environ. Sci. Technol. 1996, 30, 3544-3550. 
12. Potter, T.L.; Simmons, K.; Wu, J.; Sanchez-Olvera, M.; Kostecki, P.; Calabrese, E. Static die-away of a nonylphenol ethoxylate surfactant in estuarine water samples. Environ. Sci. Technol. 1999, 33, 113-118.

13. Lussier, S.M.; Champlin, D.; LiVolsi, J.; Poucher, S.; Pruell, R.J. Acute toxicity of para-nonylphenol to saltwater animals. Environ. Toxicol. Chem. 2000, 19, 617-621.

14. Wang, X.; Han, X.; Hou, Y.; Yao, G.; Wang, Y. Effect of nonylphenol on apoptosis of Sertoli cells in vitro. Bull. Environ. Contam. Tox. 2003, 70, 0898-0904.

15. Correa-Reyes, G.; Viana, M.T.; Marquez-Rocha, F.J.; Licea, A.F.; Ponce, E.; Vazquez-Duhalt, R. Nonylphenol algal bioaccumulation and its effect through the trophic chain. Chemosphere 2007, 68, 662-670.

16. Teneyck, M.C.; Markee, T.P. Toxicity of nonylphenol, nonylphenol monoethoxylate, and nonylphenol diethoxylate and mixtures of these compounds to Pimephales promelas (fathead minnow) and Ceriodaphnia dubia. Arch. Environ. Con. Tox. 2007, 53, 599-606.

17. Lee, P.-C.; Lee, W. In vivo estrogenic action of nonylphenol in immature female rats. Bull. Environ. Contam. Tox. 1996, 57, 341-348.

18. Goto, R.; Kubota, T.; Ibuki, Y.; Kaji, K.; Goto, A. Degradation of nonylphenol polyethoxylates by ultraviolet $\mathrm{B}$ irradiation and effects of their products on mammalian cultured cells. Toxicology 2004, 202, 237-247.

19. Zumbado, M.; Boada, L.D.; Torres, S.; Monterde, J.G.; Díaz-Chico, B.N.; Afonso, J.L.; Cabrera, J.J.; Blanco, A. Evaluation of acute hepatotoxic effects exerted by environmental estrogens nonylphenol and 4-octylphenol in immature male rats. Toxicology 2002, 175, 49-62.

20. Nair-Menon, J.U.; Campbell, G.T.; Blake, C.A. Toxic effects of octylphenol on cultured rat and murine splenocytes. Toxicol. Appl. Pharm. 1996, 139, 437-444.

21. European Commission. Directive 2003/53/EC of the European Parliament and of the Council of 18 June 2003 amending for the 26th time Council Directive 76/769/EEC relating to restrictions on the marketing and use of certain dangerous substances and preparations (nonylphenol, nonylphenol ethoxylate and cement). In Official Journal of the European Union; Publications Office of the European Union: Luxembourg City, Luxembourg. 2003; Volume 178, pp 24-178.

22. Nonylphenol (NP) and Nonylphenol Ethoxylates (NPEs) Action Plan; Available online: http://www.epa.gov/oppt/existingchemicals/pubs/actionplans/RIN2070-ZA09_NP-NPEs\%20Action\% 20Plan_Final_2010-08-09.pdf (accessed on 8 September 2010).

23. Stachel, B.; Ehrhorn, U.; Heemken, O.-P.; Lepom, P.; Reincke, H.; Sawal, G.; Theobald, N. Xenoestrogens in the River Elbe and its tributaries. Environ. Pollut. 2003, 124, 497-507.

24. Tsuda, T.; Suga, K.; Kaneda, E.; Ohsuga, M. 4-Nonylphenol, 4-nonylphenol mono-and diethoxylates, and other 4-alkylphenols in water and shellfish from rivers flowing into Lake Biwa. Bull. Environ. Contam. Tox. 2002, 68, 126-131.

25. Keith, T.L.; Snyder, S.A.; Naylor, C.G.; Staples, C.A.; Summer, C.; Kannan, K.; Giesy, J.P. Identification and quantitation of nonylphenol ethoxylates and nonylphenol in fish tissues from Michigan. Environ. Sci. Technol. 2001, 35, 10-13.

26. Ferrara, F.; Fabietti, F.; Delise, M.; Bocca, A.P.; Funari, E. Alkylphenolic compounds in edible molluscs of the Adriatic Sea (Italy). Environ. Sci. Technol. 2001, 35, 3109-3112. 
27. Jin, X.; Jiang, G.; Huang, G.; Liu, J.; Zhou, Q. Determination of 4-tert-octylphenol, 4-nonylphenol and bisphenol A in surface waters from the Haihe River in Tianjin by gas chromatography-mass spectrometry with selected ion monitoring. Chemosphere 2004, 56, 1113-1119.

28. Zgoła-Grześkowiak, A. Dispersive liquid-liquid microextraction applied to isolation and concentration of alkylphenols and their short-chained ethoxylates in water samples. J. Chromatogr. A 2010, 1217, 1761-1766.

29. Mao, Z.; Zheng, X.; Zhang, Y.; Tao, X.; Li, Y.; Wang, W. Occurrence and biodegradation of nonylphenol in the environment. Int. J. Mol. Sci. 2012, 13, 491-505.

30. Xu, J.; Wang, P.; Guo, W.; Dong, J.; Wang, L.; Dai, S. Seasonal and spatial distribution of nonylphenol in Lanzhou Reach of Yellow River in China. Chemosphere 2006, 65, 1445-1451.

31. Vega Morales, T.; Torres Padrón, M.; Sosa Ferrera, Z.; Santana Rodríguez, J. Determination of alkylphenol ethoxylates and their degradation products in liquid and solid samples. TrAC-Trend. Anal. Chem. 2009, 28, 1186-1200.

32. Solé, M.; de Alda, M.J.L.; Castillo, M.; Porte, C.; Ladegaard-Pedersen, K.; Barceló, D. Estrogenicity determination in sewage treatment plants and surface waters from the Catalonian area (NE Spain). Environ. Sci. Technol. 2000, 34, 5076-5083.

33. Nakada, N.; Tanishima, T.; Shinohara, H.; Kiri, K.; Takada, H. Pharmaceutical chemicals and endocrine disrupters in municipal wastewater in Tokyo and their removal during activated sludge treatment. Water Res. 2006, 40, 3297-3303.

34. Klecka, G.M.; Naylor, C.G.; Staples, C.A.; Losey, B. Occurrence of nonylphenol ethoxylates and their metabolites in municipal wastewater treatment plants and receiving waters. Water Environ. Res. 2010, 82, 447-454.

35. Fan, Z.; Hu, J.; An, W.; Yang, M. Detection and occurrence of chlorinated byproducts of bisphenol a, nonylphenol, and estrogens in drinking water of china: Comparison to the parent compounds. Environ. Sci. Technol. 2013, 47, 10841-10850.

36. Spehar, R.L.; Brooke, L.T.; Markee, T.P.; Kahl, M.D. Comparative toxicity and bioconcentration of nonylphenol in freshwater organisms. Environ. Toxicol. Chem. 2010, 29, 2104-2111.

37. Liu, Y.; Tam, N.F.; Guan, Y.; Yasojima, M.; Zhou, J.; Gao, B. Acute toxicity of nonylphenols and bisphenol A to the embryonic development of the abalone Haliotis diversicolor supertexta. Ecotoxicology 2011, 20, 1233-1245.

38. Preuss, T.G.; Telscher, M.; Ratte, H.T. Life stage-dependent bioconcentration of a nonylphenol isomer in Daphnia magna. Environ. Pollut. 2008, 156, 1211-1217.

39. Shan, J.; Wang, T.; Li, C.; Klumpp, E.; Ji, R. Bioaccumulation and bound-residue formation of a branched 4-nonylphenol isomer in the geophagous earthworm Metaphire guillelmi in a rice paddy soil. Environ. Sci. Technol. 2010, 44, 4558-4563.

40. Riva, C.; Porte, C.; Binelli, A.; Provini, A. Evaluation of 4-nonylphenol in vivo exposure in Dreissena polymorpha: Bioaccumulation, steroid levels and oxidative stress. Comp. Biochem. Phys. C 2010, 152, 175-181.

41. Yuan, H.X.; Xu, X.; Sima, Y.H.; Xu, S.Q. Reproductive toxicity effects of 4-nonylphenol with known endocrine disrupting effects and induction of vitellogenin gene expression in silkworm, Bombyx mori. Chemosphere 2013, 93, 263-268. 
42. Yuan, S.; Yu, C.; Chang, B. Biodegradation of nonylphenol in river sediment. Environ. Pollut. 2004, 127, 425-430.

43. Chang, B.; Yu, C.; Yuan, S. Degradation of nonylphenol by anaerobic microorganisms from river sediment. Chemosphere 2004, 55, 493-500.

44. Ahel, M.; McEvoy, J.; Giger, W. Bioaccumulation of the lipophilic metabolites of nonionic surfactants in freshwater organisms. Environ. Pollut. 1993, 79, 243-248.

45. Routledge, E.J.; Sumpter, J.P. Estrogenic activity of surfactants and some of their degradation products assessed using a recombinant yeast screen. Environ. Toxicol. Chem. 1996, 15, 241-248.

46. Sun, H.; Gu, X. Comprehensive toxicity study of nonylphenol and short-chain nonylphenol polyethoxylates on Daphnia magna. Bull. Environ. Contam. Tox. 2005, 75, 677-683.

47. Gao, Q.; Tam, N. Growth, photosynthesis and antioxidant responses of two microalgal species, Chlorella vulgaris and Selenastrum capricornutum, to nonylphenol stress. Chemosphere 2011, 82, 346-354.

48. Kumaran, S.S.; Kavitha, C.; Ramesh, M.; Grummt, T. Toxicity studies of nonylphenol and octylphenol: hormonal, hematological and biochemical effects in Clarias gariepinus. J. Appl. Toxicol. 2011, 31, 752-761.

49. Semple, K.T.; Cain, R.B.; Schmidt, S. Biodegradation of aromatic compounds by microalgae. Fems Microbiol. Lett. 1999, 170, 291-300.

50. Guolan, H.; Hongwen, S.; Li, C.L. Study on the physiology and degradation of dye with immobilized algae. Artif. Cell. Blood Sub. 2000, 28, 347-363.

51. Huang, G.; Sun, H.; Song, Z. Interactions between dibutyl phthalate and aquatic organisms. Bull. Environ. Contam. Tox. 1999, 63, 759-765.

52. Meylan, W.M.; Howard, P.H.; Boethling, R.S.; Aronson, D.; Printup, H.; Gouchie, S. Improved method for estimating bioconcentration/bioaccumulation factor from octanol/water partition coefficient. Environ. Toxicol. Chem. 1999, 18, 664-672.

53. Schwarzenbach, R.P.; Gschwend, P.M.; Imboden. D.M. Environmental organic chemistry, 2nd ed.; John Wiley \& Sons, Inc., Hoboken, NJ, USA, 2005; p. 599.

54. Snyder, S.A.; Keith, T.L.; Pierens, S.L.; Snyder, E.M.; Giesy, J.P. Bioconcentration of nonylphenol in fathead minnows (Pimephales promelas). Chemosphere 2001, 44, 1697-1702.

55. Ekelund, R.; Bergman, A.; Granmo, A.; Berggren, M. Bioaccumulation of 4-nonylphenol in marine animals-A re-evaluation. Environ. Pollut. 1990, 64, 107-120.

56. Chang, B.; Chiang, F.; Yuan, S. Anaerobic degradation of nonylphenol in sludge. Chemosphere 2005, 59, 1415-1420.

57. Chang, B.; Lu, Z.; Yuan, S. Anaerobic degradation of nonylphenol in subtropical mangrove sediments. J. Hazard. Mater. 2009, 165, 162-167.

58. Gabriel, F.L.; Heidlberger, A.; Rentsch, D.; Giger, W.; Guenther, K.; Kohler, H.-P.E. A novel metabolic pathway for degradation of 4-nonylphenol environmental contaminants by Sphingomonas xenophaga Bayram ipso-hydroxylation and intramolecular rearrangement. J. Biol. Chem. 2005, 280, 15526-15533.

59. Huang, K.; Shigeta, K.; Kunieda, H. Phase behavior of polyoxyethylene dodecyl ether-water systems. In Trends in Colloid and Interface Science XII; Steinkopff: Dresden, Germany, 1998; Volume 110, pp. 171-174. 
60. Kunieda, H.; Umizu, G.; Aramaki, K. Effect of mixing oils on the hexagonal liquid crystalline structures. J. Phys. Chem. B 2000, 104, 2005-2011.

61. Kunieda, H.; Shigeta, K.; Ozawa, K.; Suzuki, M. Self-organizing structures in poly (oxyethylene) oleyl ether-water system. J. Phys. Chem. B 1997, 101, 7952-7957.

62. Jonkers, N.; Knepper, T.P.; De Voogt, P. Aerobic biodegradation studies of nonylphenol ethoxylates in river water using liquid chromatography-electrospray tandem mass spectrometry. Environ. Sci. Technol. 2001, 35, 335-340.

63. Ahel, M.; Giger, W.; Koch, M. Behaviour of alkylphenol polyethoxylate surfactants in the aquatic environment-I. Occurrence and transformation in sewage treatment. Water Res. 1994, 28, $1131-1142$.

64. Karahan, Ö.; Olmez-Hanci, T.; Arslan-Alaton, I.; Orhon, D. Modelling biodegradation of nonylphenol ethoxylate in acclimated and non-acclimated microbial cultures. Bioresour. Technol. 2010, 101, 8058-8066.

65. Nichols, H.; Bold, H. Growth media-Freshwater. In Handbook of Physiological Methods; Stein, J.R., Ed.; Cambridge University Press: London, UK, 1973; pp. 7-24.

66. Hou, S.; Sun, H.; Gao, Y. Sorption of small metabolites of nonylphenol polyethoxylates in single and complex systems on aquatic suspended particulate matter. Chemosphere 2006, 63, 31-38.

(C) 2014 by the authors; licensee MDPI, Basel, Switzerland. This article is an open access article distributed under the terms and conditions of the Creative Commons Attribution license (http://creativecommons.org/licenses/by/3.0/). 